\begin{tabular}{|c|c|c|}
\hline 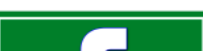 & Int.J.Curr.Microbiol.App.Sci (2021) 10(08): 164-176 & \\
\hline & $\begin{array}{l}\text { International Journal of Current Microbiology and Applied Sciences } \\
\text { ISSN: 2319-7706 Volume } 10 \text { Number } 08 \text { (2021) } \\
\text { Journal homepage: http://www.ijcmas.com }\end{array}$ & 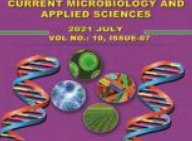 \\
\hline $\begin{array}{l}\text { EXCELLENT } \\
\text { PUBLISHERS }\end{array}$ & & \\
\hline
\end{tabular}

\title{
Isolation, Identification and Characterization of Antimicrobial Activity Exhibiting Actinomycete Streptomyces paradoxus Strain KUASN-7 from Soil
}

\author{
R. Muthuraj, Meghashyama P. Bhat, S. B. Dhanyakumara, H. M. Halaswamy, \\ K. N. Shashiraj, Bidhayak Chakraborty, S. S. Pallavi and Sreenivasa Nayaka* \\ Department of Botany, Karnatak University, Dharwad-580003, Karnataka, India \\ *Corresponding author
}

\begin{tabular}{l} 
K e y w o r d s \\
Actinomycetes, \\
$\begin{array}{l}\text { FTIR, Antibiotics, } \\
\text { Antimicrobial, } \\
\text { Streptomyces }\end{array}$ \\
\hline Article Info \\
\hline $\begin{array}{l}\text { Accepted: } \\
\text { 12 July } 2021 \\
\text { Available Online: } \\
\text { 10 August } 2021\end{array}$ \\
\hline
\end{tabular}

A B S T R A C T

Soil acts as a rich source of Actinomycetes, which are generally characterized as potent antibiotic producers. The research rationale of this study was to isolate and characterize potential Actinomycetes possessing antibiotic properties from the soils of Dharwad Karnataka, India. Further, isolates were characterized using microscopic, biochemical and molecular techniques. Initially, ten different Actinomycetes were isolated on starch casein agar media. Out of ten isolates, five of them were Grampositive and were further screened for antimicrobial potency by cross streak method. Among 5 Actinomycetes isolates studied, isolate $\mathrm{SN}-7$ was found to be most efficient against all the four pathogens tested, which confirmed its antimicrobial efficacy. The potent active isolate SN-7 was identified as Streptomyces strain by 16S rRNA gene sequence similarity analysis and given a strain no. SN-7. Genebee and NEB Cutter version 2.0 online tools were used to confirm $16 \mathrm{~S}$ rRNA gene secondary structure and restriction sites on the DNA sequence respectively, which was deposited with NCBI with an accession number KX284898, Streptomyces paradoxus strain KUASN-7. In addition, Streptomyces paradoxus strain KUASN-7 was subjected for preliminary screening of bioactive metabolites using column chromatography and the eluted fractions were further characterized using UV and FTIR spectroscopy techniques.

\section{Introduction}

Actinomycetes are Gram-positive bacteria which exhibit fungi-like characteristic morphology and comprise a high $\mathrm{G}+\mathrm{C}$ content. Studies on actinomycetes and their secondary metabolites are relatively important as they are prime sources of secondary metabolites-antibiotics (Al-Humiany et al., 2010). Further, isolation of actinomycetes from different sources is quite essential to tackle those numerous pathogens that have acquired resistance to most prescribed antibiotics and to overcome them with the unique metabolite of these diverse actinomycetes. Hence, the quest for search of 
novel metabolites antibiotics has gained significant importance in pharmaceutical industry. The soil, in particular, is an extensively exploited ecological niche and a prime source for diverse actinomycetes. Soil microorganisms produce numerous natural bioactive metabolites, including clinically important antibiotics and therapeutic molecules. However, extensive antibiotic usage has eventually lead to evolution of multi-drug resistant pathogens and thus entail discovering novel molecules, including antimicrobial that carry potential antibiotic properties. Searching for unknown microbial species is an effective approach for obtaining novel bioactive molecules (Sherman et al., 2004; Bartlett et al., 2006). Thus, there is dire necessity to find effective alternative drugs, especially antibiotics, to control and overcome the increasing spread of multi-drug resistant organisms and life-threatening diseases (Pompliano et al., 2007).

However, as numerous studies have confirmed that actinomycetes are potent source of antibiotics, especially genus Streptomyces being most abundant and diverse group inhabiting soil (Reena et al., 2012; Mukherjee et al., 2017), they have been so isolated from unique extreme habitats such as cold/ hot springs and mangroves (Mukherjee et al., 2017). Further, Streptomyces sp. have been source of several novel bioactive compounds which are antagonistic to pathogens (Bhattacharyya et al., 2015). With the advent of polymerase chain reaction and gene sequencing tools, interpretation of a closely related taxon with superior authenticity has been convenient in comparison to other conventional techniques. The notable application of molecular techniques in analysis of bacterial genomes has contributed extensively to our knowledge of bacterial diversity and taxonomy. The identification of actinomycetes using conventional techniques such as microscopic and biochemical is often unreliable, as biochemical characters of few microorganisms are unsuitable for more effective identification of species and strain (Leung et al., 2000). Hence, frequently rapid and reliable technique such as ribonucleaseresistant oligo-nucleotides of the $16 \mathrm{~S}$ ribosomal RNA (rRNA) is extensively followed for suitable identification of microorganisms (Komagata et al., 1993; Kizil et al., 2008).

Further, phylogenetic analysis of the $16 \mathrm{~S}$ rRNA gene sequence is one of the emerging key areas in the field of diversity and evolutionary studies (Sharon and Michael, 2007). The spectrometric analysis is always been the first choice for screening and identification of novel compounds irrespective of the source. UV and FTIR analysis are such spectrometric techniques which are of immense use for the detection and identification of novel bioactive compounds more specifically. Several studies have used this technique in screening and identification of compounds from microbial sources (Singh et al., 2016).

Hence, the present study was undertaken to isolate and characterize potential actinomycetes strains from the soil of Botanical garden, Karnatak University, Dharwad. Further, the promising isolates were screened for their antimicrobial ability and preliminary screening of bioactive compounds using spectroscopy.

\section{Materials and Methods}

\section{Isolation of actinomycetes from soil samples}

Soil samples were collected from different locations of Botanical garden, Karnatak University, Dharwad, Karnataka, India. The soil sample $(50 \mathrm{~g})$ was collected in sterile, autoclavable polythene bags. Soil samples (Red soil) were cleaned to remove the stones 
and debris and air dried in shade for three to four days at room temperature at 32 to $35^{\circ} \mathrm{C}$.

The standard serial dilution plate culture technique was followed for the isolation of actinomycetes. Dilutions ranging from $10^{-1}$ to $10^{-5}$ were considered for isolation. $0.1 \mathrm{ml}$ aliquot of sample from the respective dilutions was dispensed on two agar media viz. starch casein and glycerol asparagine agar (Williams and Kuster, 1964). The inoculated plates were kept for incubation at $30{ }^{\circ} \mathrm{C}$ for duration of 7 8 days. A growth characteristic of the isolates (actinomycetes) was recorded every $24 \mathrm{~h}$. The colonies identical to actinomycetes were observed under microscope and sub-cultured subsequently.

\section{Morphological and cultural characteristics}

The morphological and cultural characterization of sub-cultured/selected actinomycetes strain was determined by growing the isolates on starch casein and glycerol asparagine agar medium at $30^{\circ} \mathrm{C}$ for 7 days (Amono et al., 1987). The morphological characters viz. colony characteristics, aerial hyphae, substrate mycelium and spore were examined (Gottlieb and Shirling, 1966). The colony colors of the aerial and substrate mycelium were described according to the colors of the RALcode and arrangement of aerial hyphae and spore surface isolate colonies were subsequently observed by phase contrast microscope (Carl Zeis Axio A1) (Erko et al., 2003).

Primary Screening of antimicrobial activities of pure isolates by cross streak method

Isolated strains were subjected for evaluation of antimicrobial potential. The pathogenic bacteria such as Aspergillus fumigatus (MTCC8877), Enterobacter aerogenes (ATTC2822), Staphylococcus epidermidis
(MTCC435) and Shigella flexneri (MTCC1457) were procured from IMTECH, Chandigarh, India. Nutrient agar media was used for the antimicrobial activity and cross streak method was followed as described by Dezfully and Ramanayaka (2015). Briefly, each sterile plate was streaked with each specific isolate and incubated at $37{ }^{\circ} \mathrm{C}$ for seven to ten days. Later, $24 \mathrm{~h}$ fresh sub cultured test bacteria was prepared and streaked perpendicular to the actinomycete isolates. Then plates were incubated at $37^{\circ} \mathrm{C}$ for $24 \mathrm{~h}$. After incubation, plates were observed for inhibitory activity.

\section{Scanning electron microscopy}

After the preliminary examination of antimicrobial activity, a unique isolate which exhibited potential antimicrobial activity was further subjected for micro-morphology and external morphology studies using scanning electron microscopy (JEOL JSM-5610, Japan) and sample was prepared according to the protocol described by (Srinivasan et al., 2014).

\section{Physiological and Biochemical characteristics of the isolate}

Physiological and biochemical characterization of the unique isolates were studied to understand the basic physiology of the soil actinomycetes.

Several physiological and biochemical tests such as different $\mathrm{pH}$, temperature, Gram staining, spore staining, motility, $\mathrm{NaCl}$ tolerance, starch, casein, urea, gelatin, carbohydrate and nitrate reduction test were performed (Prakasham et al., 2014).

Genomic DNA extraction and analysis of 16S rRNA and DNA sequence

Genomic DNA was isolated following the 
protocol of Sambrook et al., (1998) and the quality of the DNA was examined by agarose gel electrophoresis. 16S rRNA genes were amplified using locus specific primers 5'GAAGCGCTCACGGCCTA-3' (forward primer) and 3'-CGGAGTGTCCATG TTCAGGGAACG-5' (reverse primer). The PCR reaction mixture contained $50 \mathrm{ng}$ of DNA, $1 \mu \mathrm{l}$ of $16 \mathrm{~S}$ forward primer (400 $\mathrm{ng}$ ) and $16 \mathrm{~S}$ reverse primer $(400 \mathrm{ng}), 4 \mu \mathrm{l}$ of dNTPs (2.5 mM each), $10 \mu \mathrm{l}$ of $10 \mathrm{X}$ Taq DNA polymerase assay buffer, $1 \mu \mathrm{l}$ of Taq DNA polymerase enzyme $(3 \mathrm{U} / \mu \mathrm{l})$, and $7 \mu \mathrm{l}$ Millipore water was added to make the total reaction volume to $100 \mu \mathrm{l}$, amplification was performed using automated thermal cycler (Model; ABI2720, Applied biosystems USA), with a following conditions; Initial denaturation at $96{ }^{\circ} \mathrm{C}$ for $5 \mathrm{~min}$ ( 25 cycles), denaturation at $96{ }^{\circ} \mathrm{C}$ for $30 \mathrm{sec}$, Extension at $50^{\circ} \mathrm{C}$ for $30 \mathrm{sec}$ and final extension at $60{ }^{\circ} \mathrm{C}$ for $1.30 \mathrm{~min}$. The PCR amplicons were examined on agarose gel electrophoresis (1\%) with the aid of $500 \mathrm{bp}$ DNA ladder. Purified PCR amplicon was sequenced (applied biosystems Sanger sequencing 3500 series genetic analyzer) and used to interrogate the NCBI database via BLAST web portal (Valan et al., 2008).

16S rRNA phylogenetic, secondary structure and restriction sites analysis

Sequenced DNA data were compiled and analyzed and matched with the GenBank database using Basic Local Alignment Search Tool (BLAST) algorithm from the NCBI website (www.ncbi.nlm.nih.gov). The DNA sequence was aligned and a phylogenetic tree was constructed by neighbor-joining method using the software MEGA4 (Tamura et al., 2007). The SN-7 culture was deposited in gene bank and the accession number is KX284898. The RNA secondary structure of the isolate Streptomyces paradoxus strain KUASN-7 was predicted, using the GeneBee online software (http://www.genebee.msu.su/ services/rna2_reduced.html) with the greedy method and restriction sites of the NRC-77 DNA were analyzed by NEB cutter V2.0 (http://tools.neb.com/NEBcutter2) (Wang et al., 2007).

\section{Preparation and preliminary characterization of crude methanolic extract}

Streptomyces paradoxus strain KUASN-7 was grown in starch casein agar media. The $\mathrm{pH}$ of the medium was adjusted to 7.0. The culture was grown with continuous shaking on a rotary shaker $(150 \mathrm{rpm})$ at $30^{\circ} \mathrm{C}$ for 14 days. After fermentation of the culture, biomass was harvested by centrifugation $(5000 \mathrm{rpm})$ at 20 ${ }^{\circ} \mathrm{C}$ for 20 minutes and then the mycelia were washed thrice with sterile distilled water under aseptic conditions. The washed fraction was finely homogenised with the aid of mortar and pestle and subsequently methanol was added in the ratio of $1: 1(\mathrm{w} / \mathrm{v})$ and mixture was allowed to mix in orbital shaker for overnight. Finally, the extract was filtered using Whatman filter paper (no.1). The filtrate was then dried using a rotary evaporator (maintained at $50{ }^{\circ} \mathrm{C}$ ). The semi dried extract was then collected in clean glass vials and stored at $4{ }^{\circ} \mathrm{C}$ for further analysis (Augustine et al., 2005). The crude methanol extract was chromatographed over a silica gel column chromatography (60x120 mesh Ramken Sigel) and eluted with mixtures of $\mathrm{CHCl}_{3}: \mathrm{MeOH}$ (chloroform: methanol; 60:40). Finally, fractions were collected and subjected for further analysis (Saravana et al., 2014). The methanolic extract was analysed using PerkinElmer Lambda 30 UV/VIS spectrophotometer (AH and Aysel 2003) in UV region (190 to $700 \mathrm{~nm}$ ). FTIR analysis of active extract was performed using Shimadzu IR-470 plus with scanning mode from 400 to $4000 \mathrm{~cm}^{-1}$ range and plotted as intensity versus wave number (Al-Humiany et al., 2010). 


\section{Results and Discussion}

\section{Screening and isolation of potential isolates}

The unique and clearly distinguishable typical colonies of microbial isolates were seen after 7 days incubation. In the dilution plate pigmented, powdery, smooth and rough colonies of actinomycetes were observed. Ten actinomycetes were isolated from soil samples from botanical garden of Karnatak University, Dharwad. Out of 10 isolates, five isolates were found to be Gram-positive bacteria and inoculated in starch casein agar (SCA) media for further analysis. The morphological appearances of isolates are depicted in Figure 1. The growth characteristics of five strains in different media are summarized in Table 1. Actinomycetes considered as prolific producers of novel antimicrobial agents and thus huge numbers of these antimicrobial compounds are discovered by screening natural habitats such as soil, water and extreme environments (Duraipandiyan et al., 2010; Zotchev, 2011). A vast taxonomic range of actinomycetes known to produce secondary metabolites with potential biological activities such as antibiotics, antifungal, anticancer, antiviral, immunosuppressant and other industrially important compounds (Newman and Cragg, 2007). The organisms showing moderate to excellent growth on SCA and GAA media showed varying pigment patterns.

Color of the substrate mycelium and aerial spore mass varied distinctly. The five isolates showed different colors of pigmentation $\mathrm{SN}-1$, SN-4 and SN-7 showed white color, while $\mathrm{SN}-2$ and $\mathrm{SN}-3$ showed blue and grey color, respectively. The observations made in the present study were in accordance with the existing literature (Ndonde and Semu, 2000; Rizk et al., 2007).

\section{Antimicrobial activity}

Five promising isolates were then evaluated for their inhibitory activity against three bacterial pathogens and one fungal pathogen by cross streak method. The antimicrobial activity is tabulated in Table 2. Out of 5 isolates, $\mathrm{SN}-1$ and $\mathrm{SN}-3$ showed no inhibition against tested pathogens, Whereas, $\mathrm{SN}-2$ showed very minimal activity against $S$. epidermidis (MTCC435) and SN-4 exhibited antibacterial activity against $S$. flexneri (MTCC1457) strains. However, SN-7 inhibited the growth of all four pathogens $[A$. fumigatus (MTCC8877), E. aerogenes (ATTC2822), S. epidermidis (MTCC435) and S. flexneri (MTCC1457)] tested indicating potential antimicrobial activity against test microorganisms. Screening of antimicrobial activity of five isolates against four pathogenic organisms showed that SN-7 exhibited maximum zone of inhibition Figure $1 \mathrm{a}$ and $1 \mathrm{~b}$. Thakur et al., (2007) reported the similar observation, wherein they isolated 110 actinomycetes strains from the forest soil of North East India and strains were characterized by conventional methods followed by assessment for their antagonistic activity against test microorganisms.

\section{Scanning electron micrograph (SEM)}

The scanning electron micrograph of promising strain SN-7 is depicted in Figure 1. The image shows aerial mycelium with cells of $1.25 \mu \mathrm{m}$ (approx) in size arranged in pseudo hyphal form. 
Table.1 Cultural characteristic of active isolates of actinomycetes

\begin{tabular}{|c|c|c|c|c|c|}
\hline Isolates & Medium & Growth & Aerial mycelium & Substrate mycelium & Pigment \\
\hline \multirow[t]{2}{*}{ SN-1 } & SCA & Moderate to good & \multirow[t]{2}{*}{ White } & \multirow[t]{2}{*}{ Colorless to white } & \multirow[t]{2}{*}{ White } \\
\hline & GAA & Poor & & & \\
\hline \multirow[t]{2}{*}{ SN-2 } & SCA & Good & \multirow[t]{2}{*}{ Grey beige } & \multirow[t]{2}{*}{ Blue } & \multirow[t]{2}{*}{ Blue } \\
\hline & GAA & Moderate to Poor & & & \\
\hline \multirow[t]{2}{*}{ SN-3 } & SCA & Good & \multirow[t]{2}{*}{ Olive yellow } & \multirow[t]{2}{*}{ Light yellow } & \multirow[t]{2}{*}{ Grey } \\
\hline & GAA & Poor & & & \\
\hline \multirow[t]{2}{*}{ SN-4 } & SCA & Moderate to good & \multirow[t]{2}{*}{ Signal white } & \multirow[t]{2}{*}{ White } & \multirow[t]{2}{*}{ White } \\
\hline & GAA & Moderate to good & & & \\
\hline \multirow[t]{2}{*}{ SN-7 } & SCA & Good & \multirow[t]{2}{*}{ Grey white } & \multirow[t]{2}{*}{ White } & \multirow[t]{2}{*}{ White } \\
\hline & GAA & Moderate to Poor & & & \\
\hline
\end{tabular}

Legend: $\mathrm{SCA}=$ Starch casein agar media; $\mathrm{GAA}=$ Glycerol aspergine agar media

Table.2 Primary screening of active isolates of actinomycetes using cross streak method against pathogenic organisms

\begin{tabular}{|c|c|c|c|c|c|}
\hline Microbes & SN-1 & SN-2 & SN-3 & SN-4 & SN-7 \\
\hline A. fumigatus (MTCC8877) & - & - & - & - & +++ \\
\hline E. aerogenes (ATTC2822) & - & - & - & - & +++ \\
\hline S. epidermidis (MTCC435), & - & + & - & - & +++ \\
\hline S. flexneri (MTCC1457) & - & - & - & + & +++ \\
\hline
\end{tabular}

Legend: +++ - Good activity, ++ - Moderate activity, + - Weak activity, - - No activity

Fig.1 Characterization of isolate of Streptomyces strain SN-7: Morphology of sporophores studied by scanning electron microscopy (A). Zone of inhibition against pathogenic bacteria by cross streak method (B and C)
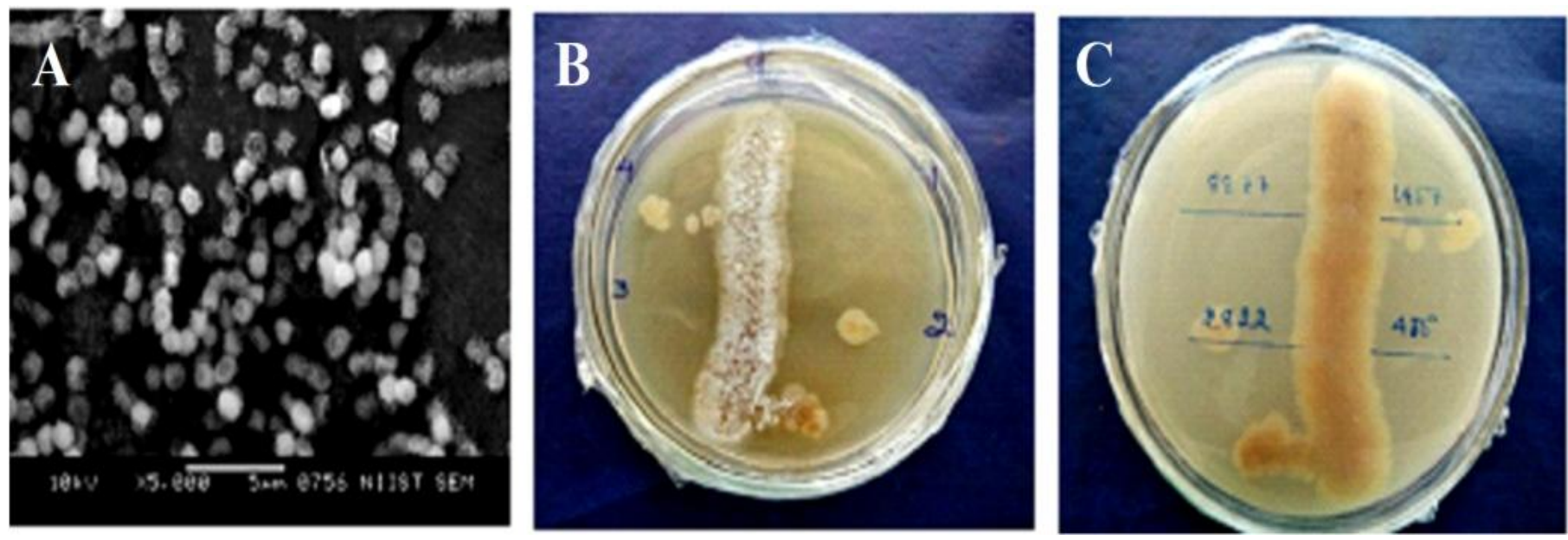
Table.3 Physiological and Biochemical characteristics of the strain SN-7

\begin{tabular}{|c|c|}
\hline Test & SN-7 \\
\hline Growth at $\mathbf{~ p H}$ & \\
\hline pH6.0 & - \\
\hline pH6.5 & - \\
\hline pH7.0 & ++ \\
\hline pH7.5 & +++ \\
\hline pH8.0 & + \\
\hline Growth at Temperature & \\
\hline $\mathbf{2 0}^{\circ} \mathrm{C}$ & - \\
\hline $\mathbf{2 5}^{\circ} \mathrm{C}$ & \\
\hline $\mathbf{3 0}^{\circ} \mathrm{C}$ & + \\
\hline $\mathbf{3 5}^{\circ} \mathrm{C}$ & +++ \\
\hline $\mathbf{4 0}^{\circ} \mathrm{C}$ & - \\
\hline Gram staining & + \\
\hline Spore staining & + \\
\hline Motility & - \\
\hline NaCl tolerance & + \\
\hline Substrate Hydrolysis & \\
\hline Starch & +++ \\
\hline Casein & +++ \\
\hline Urea & +++ \\
\hline Gelatin & +++ \\
\hline Carbohydrate & ++ \\
\hline Nitrate reduction & ++ \\
\hline
\end{tabular}

Legend: - - No growth, + - Normal growth, ++ - Moderate growth, +++ - Optimum growth

Table.4 FTIR absorption peaks and their associated functional groups detected in the Streptomyces strain SN-7 extract

\begin{tabular}{|c|c|c|}
\hline Sl. No. & Absorption peak $\left.\mathbf{( c m}^{-\mathbf{1}}\right)$ & Functional groups \\
\hline $\mathbf{1}$ & 618 & C-Br stretching alkyl halides \\
\hline $\mathbf{2}$ & 868 & C-Cl stretching alkyl halides \\
\hline $\mathbf{3}$ & 1048 & C-N stretching aliphatic amines \\
\hline $\mathbf{4}$ & 1079 & C-N stretching aliphatic amines \\
\hline $\mathbf{5}$ & 1112 & C-N stretching aliphatic amines \\
\hline $\mathbf{6}$ & 1241 & C-H wag alkyl halides \\
\hline $\mathbf{7}$ & 1386 & $\mathrm{CH}_{2}$ waging mode alkanes \\
\hline $\mathbf{8}$ & 1404 & C-C stretching aromatics \\
\hline $\mathbf{9}$ & 1465 & C-H bend alkanes \\
\hline $\mathbf{1 0}$ & 1580 & 1,3 Diketones of enol \\
\hline $\mathbf{1 1}$ & 1638 & N-H bending $1^{\mathbf{o}}$ amines \\
\hline $\mathbf{1 2}$ & 2852 & C-H stretching alkanes \\
\hline $\mathbf{1 3}$ & 2923 & H-C $=$ O:C-H stretching aldehyde \\
\hline $\mathbf{1 4}$ & 2957 & C-H stretching alkanes \\
\hline $\mathbf{1 5}$ & 3420 & O-H stretch alcohol \\
\hline & & \\
\hline
\end{tabular}


Fig.2 (a) Gel image showing the amplified product of SN-7, (b) Phylogenetic analysis of 16S rRNA gene sequence of SN-7.
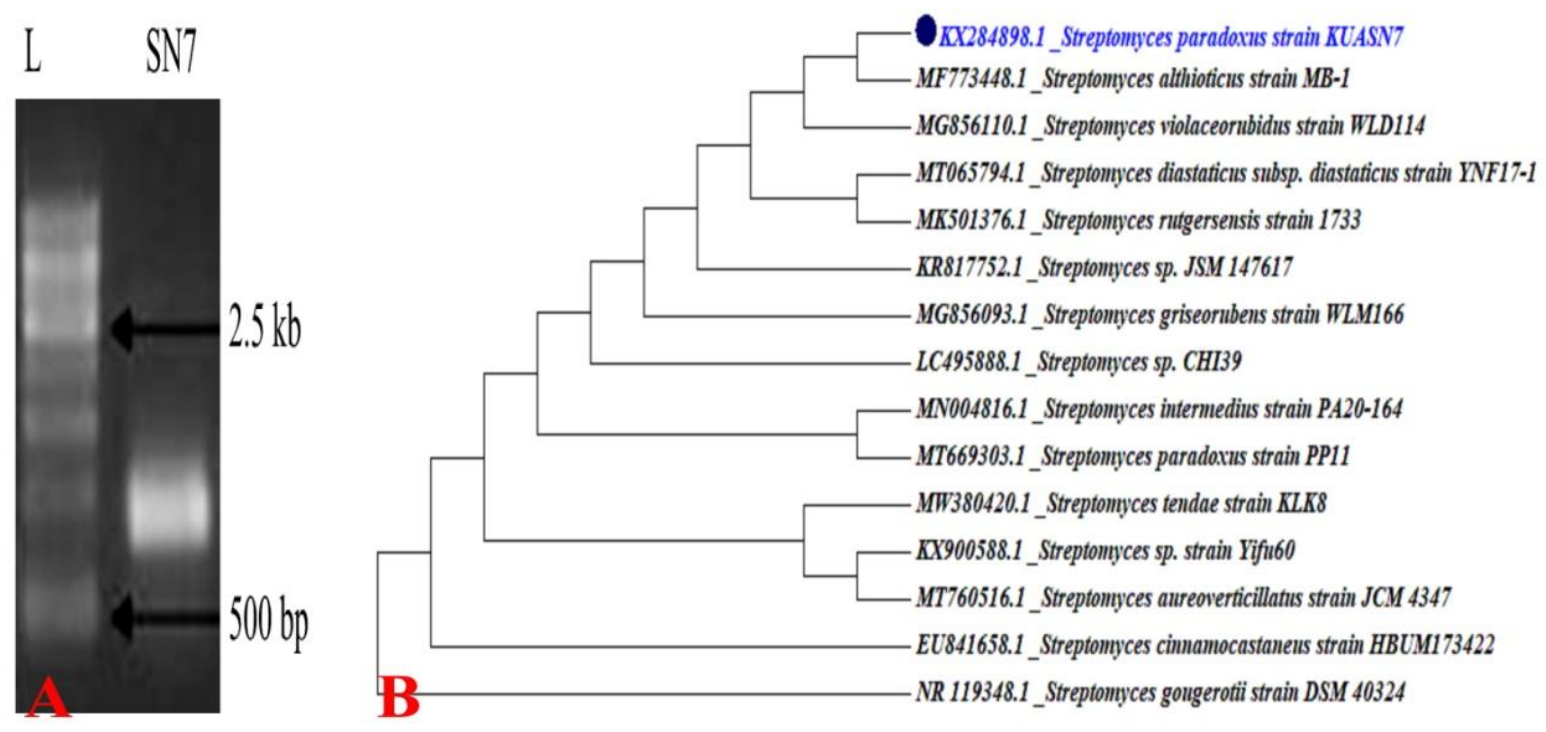

Fig.3 Secondary structure of 16S rRNA sequence of Streptomyces paradoxus strain KUASN7

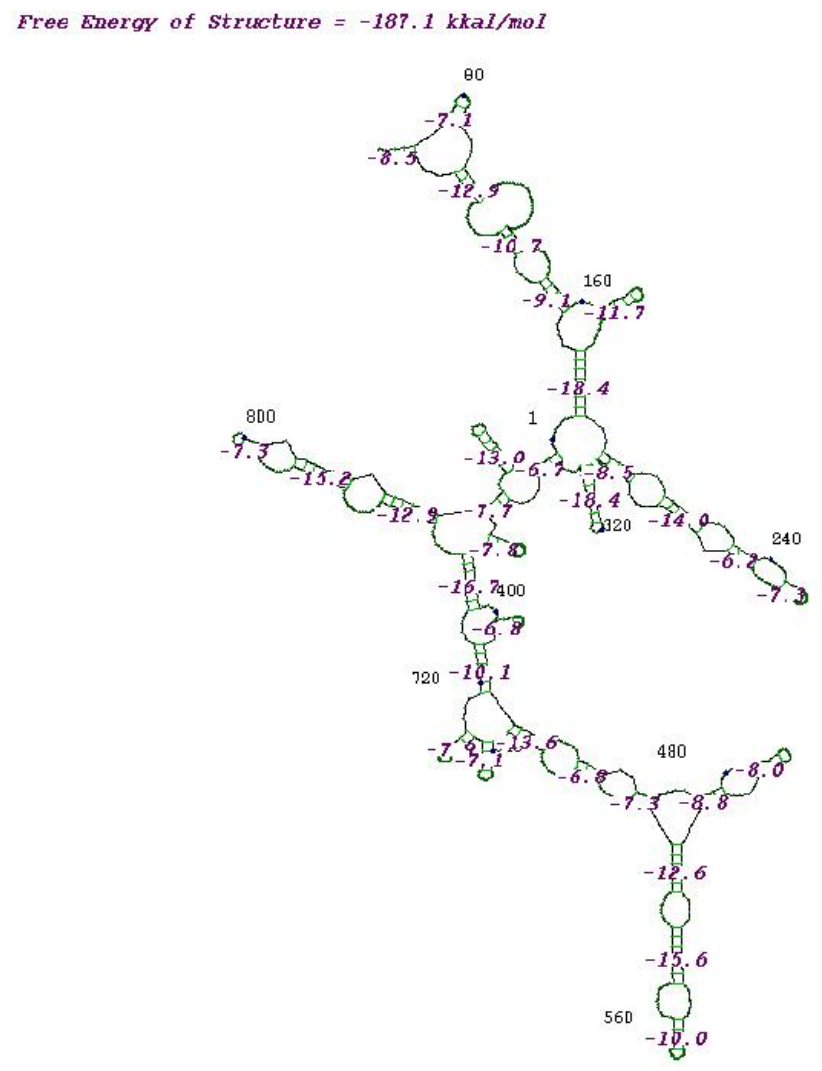


Fig.4 Restriction sites on the 16S rRNA gene sequence of Streptomyces strain SN-7

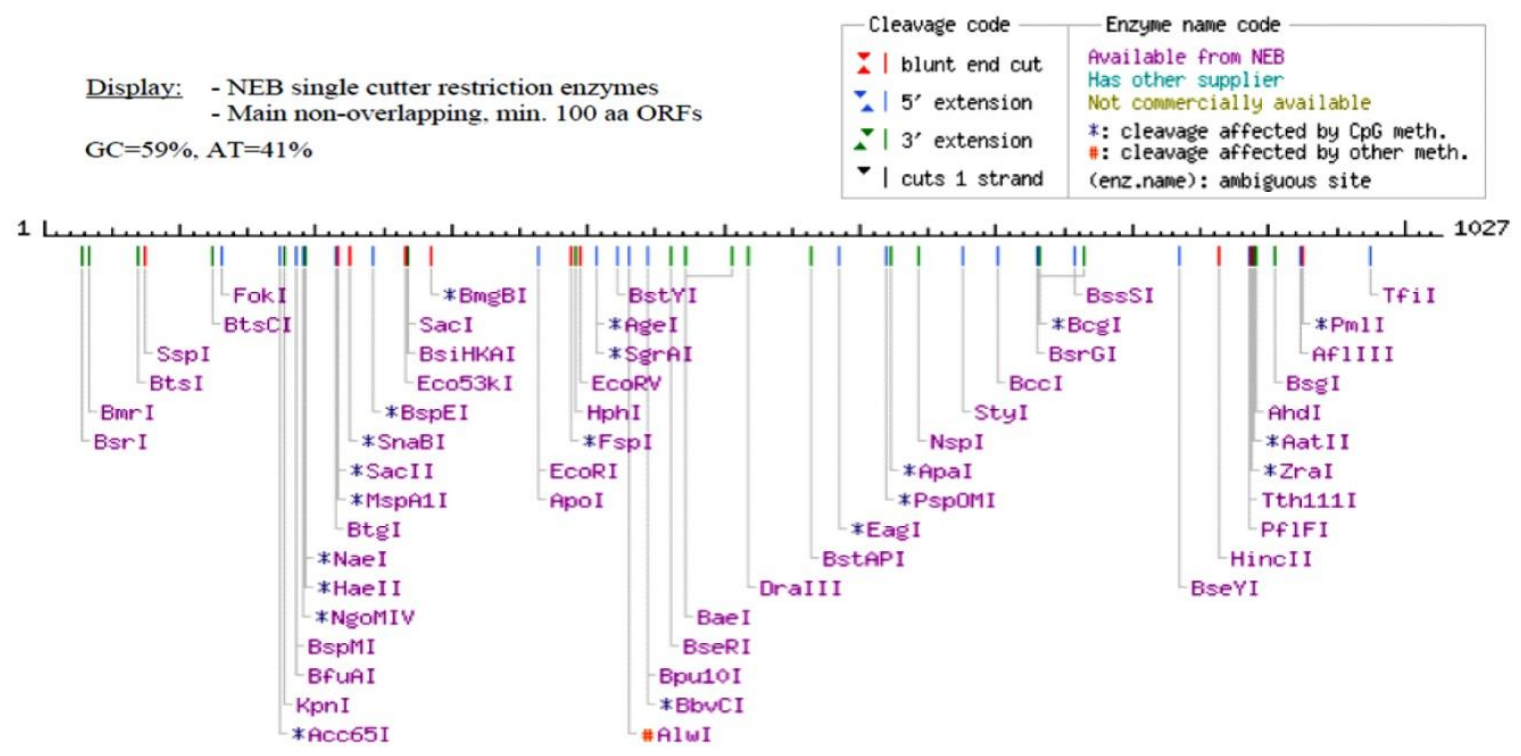

Fig.5 UV-Spectrum of Streptomyces strain SN-7

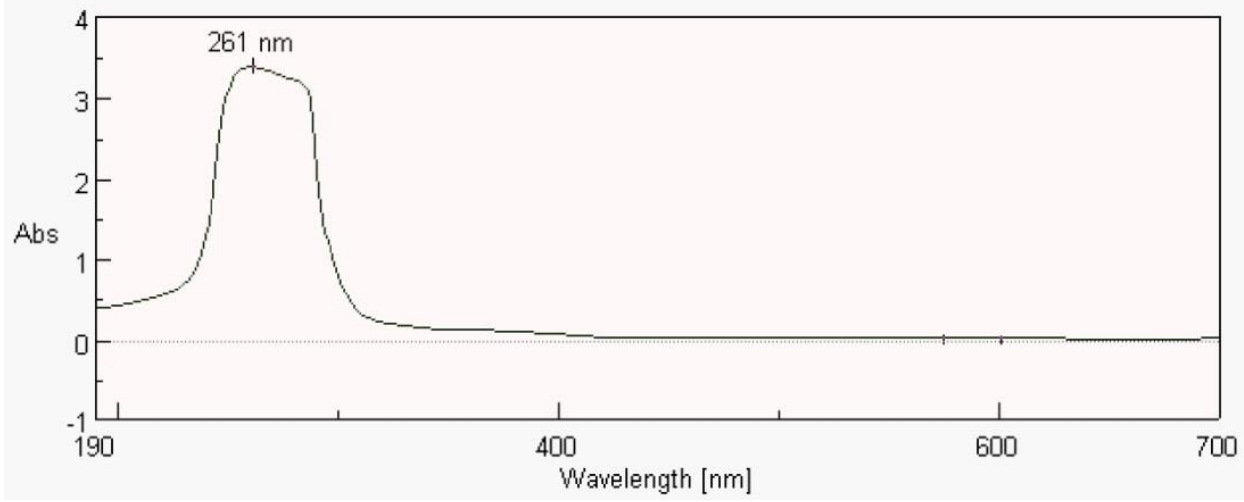

Fig.6 FTIR spectrum of Streptomyces strain SN-7

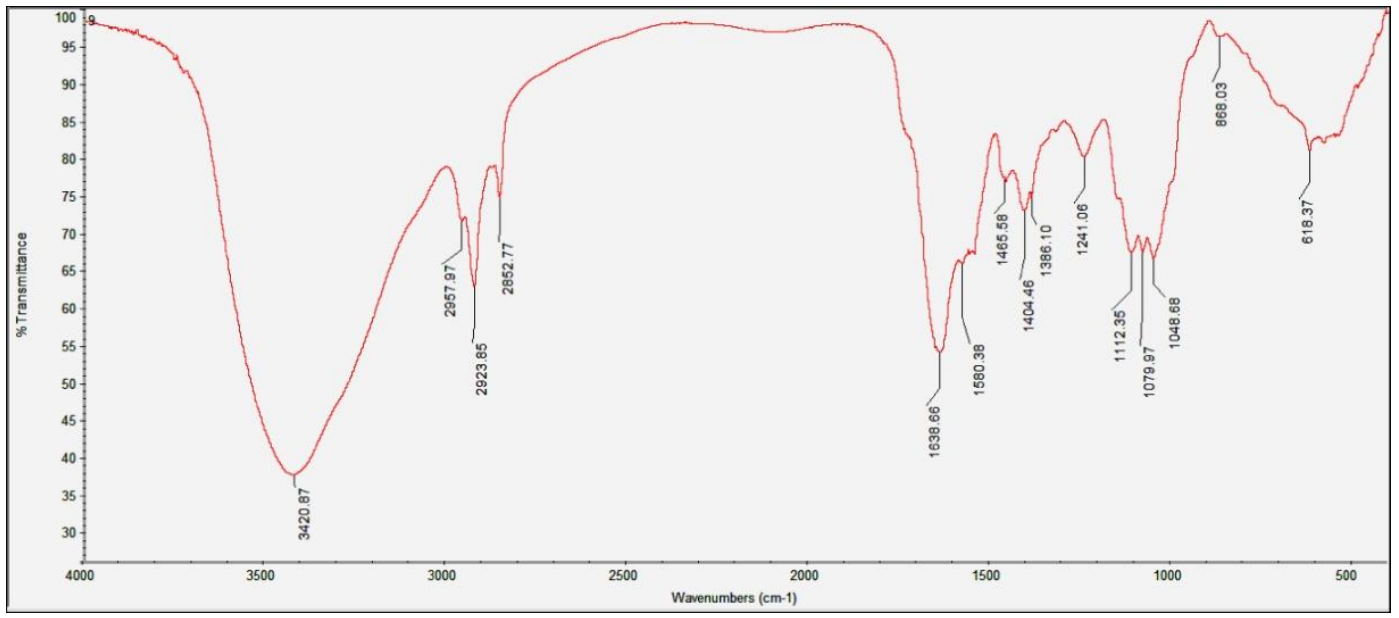


$\begin{aligned} & \text { Physiological and } \\ & \text { characteristics of isolate SN-7 }\end{aligned}$

The physiological and biochemical characteristics of isolate $\mathrm{SN}-7$ is summarized in Table 3. The SN-7 isolate at various $\mathrm{pH}$ levels for the growth and pigment production was found to be 5.0 to 8.0. The culture showed optimum growth and pigmentation at $\mathrm{pH}$ 7.5. However, pH below 7.5 and above 7.5 did not show any significant effect on growth and pigment production. Further, Growth characteristics of $\mathrm{SN}-7$ at different temperature range $\left(20{ }^{\circ} \mathrm{C}\right.$ to $\left.40{ }^{\circ} \mathrm{C}\right)$ showed optimum growth and pigmentation at $35{ }^{\circ} \mathrm{C}$. SN-7 showed positive results against gram staining and spore staining. The biochemical characteristics of isolate $\mathrm{SN}-7$ showed positive results against gram staining, spore staining, $\mathrm{NaCl}$ tolerance, hydrolysis of starch, casein, urea, and gelatin and motility test is negative, The carbohydrate fermentation and nitrogen reduction tests also showed positive results. The biochemical and physiological characteristics of the isolates differ from isolate to isolate and mainly depends on the growth conditions. In the present study physiological characteristics of $\mathrm{SN}-7$ varied depending on the available nutrients in the medium and the physical conditions. Thus, it is concluded that on the basis of the present and previous studies that the nutrient compositions of the medium greatly influence the growth and morphology of organisms (Kamil et al., 2014).

\section{$16 \mathrm{~S}$ rRNA gene sequencing of isolate $\mathrm{SN}-7$}

In this result the active isolate $\mathrm{SN}-7$ was identified as Streptomyces sp. based on the 16S rRNA gene sequence of the isolate and its phylogeny. Recent studies indicate that phylogenetic analysis has been key technique in the identification of Streptomyces sp. Several new species have been validated such as Streptomyces thermoalcaltolerans, Streptomyces thermocarboxydovorans and Streptomyces viridis isolated from different habitats (Song et al., 2001). Further, 16S rRNA secondary structure and restriction site analysis of Streptomyces strain. SN-7 showed GC and AT content of $58 \%$ and $42 \%$, respectively. The genomic DNA of SN-7 strain was isolated, analyzed by PCR amplification. The amplified product obtained and gel purified was further sequenced. A 1027 bp long, 16S rRNA partial gene sequence of isolate $\mathrm{SN}-7$ was subjected to BLAST analysis, which confirmed that the SN-7 isolate belonged to the Streptomyces sp. (Figure 2a). The sequence of $1027 \mathrm{bp}$ shared 98\% sequence similarity with Streptomyces strain. The DNA sequences were aligned and a phylogenetic tree was derived by using MEGA4 software (Figure 2b).

The secondary RNA structure of $\mathrm{SN}-7$ isolate 16S rRNA sequence was predicted (Figure 3). This prediction showed free energy of the structure as $-238.8 \mathrm{kcal} / \mathrm{mol}$, the threshold energy as -4.0 with cluster factor, conserved factor 2 and compensated factor 4 and the conservative factor of 0.8 . The prediction of restriction sites in the strain $\mathrm{SN}-7$ showed the restriction sites for various enzymes, such as Bsr l, Bmr l, Bts l, Ssp l, Btsc I and Fok I and possess GC and AT content of $58 \%$ and $42 \%$, respectively (Figure 4).

UV-Visible Spectrophotometer and Fourier-transform infrared spectroscopy analysis of Streptomyces strain SN-7

The analysis indicated that methanolic extract comprised multiple functional groups. The UV spectral data for methanol extract of Streptomyces strain SN-7 fractions of column chromatography, the bioactive fraction exhibited a maximum UV absorption at 261 $\mathrm{nm}$ (Figure 5) and revealed the presence of 
single major peak at $261 \mathrm{~nm}$. A similar observation has been reported previously (Cai et al., 2008; Saravana et al., 2014). FTIR study was carried out for identification of biomolecules present in the extract $\mathrm{SN}-7$, the spectrum reveals that IR bands at 3420,2957 , 2852, 1638, 1580, 1465, 1404, 1386, 1241, 1112, 1079, 1048, 868 and $618 \mathrm{~cm}^{-1}$ (Figure 6 and Table 4). The band at $3420 \mathrm{~cm}^{-1}$ can be attributed to free $\mathrm{OH}$ stretching vibrations of alcohol. The sharp bands at $2923 \mathrm{~cm}^{-1}$ arise from stretching modes of aldehydic groups, whereas sharp bands at $1638 \mathrm{~cm}^{-1}$ correspond to $\mathrm{N}-\mathrm{H}$ bending amines. The three medium peaks at 1048, 1079 and $1112 \mathrm{~cm}^{-1}$ may be from aliphatic amines of $\mathrm{C}-\mathrm{N}$ stretching and band at $1386 \mathrm{~cm}^{-1}$ is due to $\mathrm{CH}_{2}$ waging mode of alkanes. The peak at fingerprint region 618 and $868 \mathrm{~cm}^{-1}$ is assigned to carbonyl stretching of alkyl halides, these biomolecules are present in the KUASN-7 extract. Some important functional groups detected were alkyl halides, aliphatic amines, alkanes, aldehyde and alcohol group.

Currently, microbial infections have become a major clinical threat and are generally associated with a very high morbidity and mortality mainly due to the development of resistance by pathogens against existing antimicrobial agents. Therefore, antimicrobial susceptibility testing and discovery of novel antimicrobial agents have been extensively explored and continue to be developed. Findings from present study reveal that Streptomyces paradoxus strain KUASN-7 isolate shows promising antimicrobial properties. Further analysis is needed for purification and characterization of the purified secondary metabolite from SN-7 potent isolate.

\section{Acknowledgement}

The financial support received from the UGCSAP-DSA-1, Department of Botany, Karnatak
University, Dharwad, Karnataka, India, is gratefully acknowledged. The authors also thank USIC, Karnatak University, Dharwad for necessary instrument facility.

\section{References}

Al-Humiany, A., Atta, H. M., Bayoumi, R., ElSehrawi, M., Aboshady, A. 2010. Biotechnological application for producing some antimicrobial agents by actinomycetes isolates from Al-khurmah Governorate. Eur. J. Appl. Physiol. 2(3): 98-107. Corpus ID: 54035807

Amono, S., Shomura, T., Gomi, S., Ito, M., Yoshida, J., Tanaka, E. 1987. Studies on new antibiotics SF2415. I. taxonomy, fermentation, isolation, physicochemical properties and biological activities. $J$. Antibiot. 11: 732-739. https://doi.org/10.7164/antibiotics.40.732

Augustine, S. K., Bhavsar, S. P., Kapadnis, B. P. 2005. A non-polyene antifungal antibiotic from Streptomyce salbidoflavus PU 23. J. Biosci. 30(2): 201-211. https://doi.org/10.1007/bf02703700

Bhattacharyya, M., Sengupta, S., Pramanik, A., Ghosh, A. 2015. Antimicrobial activities of actinomycetes isolated from unexplored regions of Sundarbans mangrove ecosystem. BMC Microbiology. 15: 170. https://doi.org/10.1186/s12866-015-0495-4

Cai, G. L., Wei, C. L., Ji, Y. Q., Hui, M. W., Ting, L., De, W. L. 2008. Identification of an antifungal metabolite produced by a potential biocontrol actinomyces strain A01. Braz. J. Microbiol. 39: 701-707. https://doi.org/10.1590/s151783822008000400020

Dezfully, N. K., Ramanayaka, J. G. 2015. Isolation, identification and assessment of antimicrobial activity of Streptomyces flavogriseus, strain ACTK2 from Soil Sample of Kodagu, Karnataka State (India). Jundishapur J.Microbiol. 8(2): 1-8. https://doi.org/10.5812/jjm.15107

Duraipandiyan, V., Sasi, A. H., Islam, V. I. H., Valanarasu, M., Ignacimuthu, S. (2010). Antimicrobial properties of actinomycetes from the soil of Himalaya. J Mycol. Med. 
20: $\quad 15-20 . \quad$ https://doi.org/10.1016/j. mycmed.2009.11.002

Erko, S., Joachim, W., Kroppenstedt, R. M., Seibert, G. 2003. Actinomaduranamibiensis sp. Nov. Int. J. Syst. Evol. 53: 721-724. https://doi.org/10.1099/ijs.0.02286-0

Gottlieb, D., Shirling, E. B. 1966. Methods for characterization of Streptomyces species. Int. J. Syst. Evol. 16: 313-340. https://doi.org/10.1099/00207713-16-3-313

Kamil, I., Talha, G., Fadime, O. K., Elif, C. 2014. Molecular identification of different actinomycetes isolated from East Black Sea region plateau soil by $16 \mathrm{~S}$ rDNA gene sequencing. Afr. J. Microbiol. Res. 8(9): 878-887.

https://doi.org/10.5897/ajmr2013.6174

Kizil, M., Yilmaz, E. I., Yavuz, M. 2008. Molecular characterization of rhizospheric soil Streptomycetes isolated from indigenous Turkish plants and their antimicrobial activity. World J. Microbiol. Biotechnol. 24(8): 1461-1470. https://doi.org/10.1007/s11274-007-9628-8

Komagata, K., Park, Y. H., Suzuki, K. I., Yim, D. G., Lee, K. C., Kim, E., Yoon, J. S., Kim, S. J., Kho, Y. H., Goodfellow, M. 1993. Suprageneric classification of peptidoglycan group B actinomycetes by nucleotide sequencing of $5 \mathrm{~S}$ ribosomal RNA. Antonie van Leeuwenhoek. 64(3-4): 307-313.

https://doi.org/10.1007/bf00873089

Leung, P. K., Woo, P. C., Leung, K. W. 2000. Identification by $16 \mathrm{~S}$ ribosomal RNA gene sequencing of an Enterobacteriaceae species from a bone marrow transplant recipient. Molecular Pathology. 53: 211215. https://doi.org/10.1136/mp.53.4.211

Mukherjee, J., Biswas, K., Choudhury, J. D., Mahansaria, R., Saha, M. 2017. Streptomyces euryhalinus sp. nov., a new actinomycete isolated from a mangrove forest. J. Antibiot. 70(6): 747-753. https://doi.org/10.1038/ja.2017.3

Ndonde, M. J. M., Semu, E. 2000. Preliminary characterisation of some Streptomyces species from four Tanzanian soils and their antimicrobial potential against selected plant and animal pathogenic bacteria. World J. Microbiol. Biotechnol. 16: 595-
599.

https://doi.org/10.1023/A:1008916418258

Newman, D. J., Cragg, G. M. 2007. Natural products as sources of new drugs over the last 25 years. J. Nat. Prod. 70: 461-477. https://doi.org/10.1021/np068054v

Pompliano, D. L., Payne, D. J., Gwynn, M. N., Holmes, D. J. 2007. Drugs for bad bugs: confronting the challenges of antibacterial discovery. Nat. Rev. Drug Discov. 6: 29-40. https://doi.org/10.1038/nrd2201

Prakasham, R. S., Sudheer, K. B., Vinay, B. T., Yaswanth, V. V. N., Jamal, A. 2014. Production of polypeptide antibiotic from Streptomycesparvulus and its antibacterial activity. Braz. J. Microbiol. 45(1): 303-312. https://doi.org/10.1590/s151783822014005000022

Reena, A., Valli, S., Suvathi, S. S., Aysha, O., Nirmala, P., Vinoth, K. P. 2012. Antimicrobial potential of Actinomycetes species isolated from marine environment. Asian Pac. J. Trop. Biomed. 2(6): 469-473. https://doi.org/10.1016/s22211691(12)60078-1

Rizk, M., Tahany, A. R., Hanaa, M. 2007. Screening of antagonistic activity in different Streptomyces species against some pathogenic microorganisms. J. Biol. Sci. 7: 1418-1423.

Sambrook, J., Fritsch, E. F., Maniatis, T. 1998. Molecular Cloning, A laboratory Manual, 2nd Edn, Cold Spring Harbor Laboratory Press, New York, USA.

Saravana, K. V., Duraipandiyan, B., Ignacimuthu, S. 2014. Isolation, screening and partial purification of antimicrobial antibiotics from soil Streptomyces sp. SCA 7. Kaohsiung J. Med. Sci. 30: 435-446. https://doi.org/10.1016/j.kjms.2014.05.006

Sharon, A. L., Michael, J. J. 2007. 16S rRNA gene sequencing for bacterial identification in the diagnostic laboratory: Pluses, Perils, and Pitfalls. J. Clin. Microbiol. 45(9): 27612764. https://doi.org/10.1128/jcm.01228-07

Sherman, D., Magarvey, N. A., Keller, J. M., Bernan, V., Dworkin, M. 2004. Isolation and characterization of novel marinederived actinomycete taxa rich in bioactive metabolites. Appl. Environ. Microbiol. 70: 7520-7529. 
https://doi.org/10.1128/aem.70.12.75207529.2004

Singh, V., Haque, S., Singh, H., Verma, J., Vibha, K., Singh, R., Jawed, A. Thripathi, C.K M. 2016. Isolation, Screening, and Identification of Novel Isolates of Actinomycetes from India for Antimicrobial Applications. Front. microbiol. $\quad 7$ : 1921. https://doi.org/10.3389/fmicb.2016.01921

Song, J., Weon, H. Y., Yoon, S. H., Park, D.S., Go, S. J., Suh, J. W. 2001. Phylogenetic diversity of Thermophilic actinomycetes and Thermoactinomyces spp. isolated from mushroom composts in Korea based on 16S rRNA gene sequence analysis. FEMS Microbiol. Lett. 202(1): 97-102. https://doi.org/10.1111/j.15746968.2001.tb10786.x

Srinivasan, V., Nagaraja, M., Parthasarathi, A. 2014. Highly deviated asymmetric division in very low proportion of mycobacterial mid-log phase cells. Open Microbiol. J. 8: 40-50.

https://doi.org/10.2174/1874285801408010 040

Bartlett, J. G., Talbot, G. H., Bradley, J., Edwards, J. E., Gilbert, D., Scheld, M. 2006. Bad bugs need drugs: an update of the development pipeline from the antimicrobial task force of the infectious diseases society of America. Clin. Infect. Dis. $\quad$ 42: 657-668. https://doi.org/10.1086/499819

Tamura, K., Dudley, J., Nei, M., Kumar, S. 2007.
Molecular evolutionary genetics analysis (MEGA) software version 4.0. Mol. Biol. Evol. 24: 1596-1599. https://doi.org/10.1093/molbev/msm092

Thakur, D., Yadav, A., Gogoi, B. K., Bora, T. C. 2007. Isolation and screening of Streptomyces in soil of protected forest areas from the states of Assam and Tripura, India, for antimicrobial metabolites. $J$. Mycol. $\quad$ Med. 17: 242-249. https://doi.org/10.1016/j.mycmed.2007.08.0 01

Valan, A. M., Duraipandiyan, V., Agastian, P., Ignacimuthu, S. 2008. Antimicrobial activity of Streptomyces sp. ERI-26 recovered from Western Ghats of Tamil Nadu, J Mycol Med. 18: 147-153. https://doi.org/10.1016/j.mycmed.2008.07.0 04

Wang, Q., Garrity, G. M., Tiedje, J., Cole, J. R. 2007. Native Bayesian classifier for rapid assignment of rRNA sequences into the new bacterial taxonomy. Appl. Environ. Microbiol. $\quad$ 73(16): 5261-5267. https://doi.org/10.1128/aem.00062-07

Williams, S. T., Kuster, E. 1964. Selection of media for isolation of Streptomycetes. Nature, $\quad 202$ : 928-929. https://doi.org/10.1038/202928a0

Zotchev, S. B. 2011. Marine actinomycetes as an emerging resource for the drug development pipelines. J. Biotechnol. 158: 168-175. https://doi.org/10.1016/j.jbiotec.2011.06.00 2

\section{How to cite this article:}

Muthuraj, R., Meghashyama P. Bhat, S. B. Dhanyakumara, H. M. Halaswamy, K. N. Shashiraj, Bidhayak Chakraborty, S. S. Pallavi and Sreenivasa Nayaka. 2021. Isolation, Identification and Characterization of Antimicrobial Activity Exhibiting Actinomycete Streptomyces paradoxus Strain KUASN-7 from Soil. Int.J.Curr.Microbiol.App.Sci. 10(08): 164-176. doi: https://doi.org/10.20546/ijcmas.2021.1008.021 